\title{
Challenges of Mega Cities: Lessons for Evolving Sustainable Nigerian Cities
}

\author{
Akubue Jideofor Anselm \\ Faculty of Environmental Sciences, Baze University, Abuja, Nigeria \\ Email: akjideofor@yahoo.com
}

How to cite this paper: Anselm, A.J. (2019) Challenges of Mega Cities: Lessons for Evolving Sustainable Nigerian Cities. Modern Economy, 10, 2031-2050. https://doi.org/10.4236/me.2019.109128

Received: August 14, 2019

Accepted: September 9, 2019

Published: September 12, 2019

Copyright $\odot 2019$ by author(s) and Scientific Research Publishing Inc. This work is licensed under the Creative Commons Attribution International License (CC BY 4.0).

http://creativecommons.org/licenses/by/4.0/

\section{c) (i) Open Access}

\begin{abstract}
The current Millennium Development Goals call for a re-thinking of city development cooperation as majorly urban. This article builds upon the lessons learnt from existing modern day megacities. It dwells upon the events that were triggered by urbanization leading to the modern day mega cities and their challenges in the process of evolving more sustainable structure in the $21^{\text {st }}$ century. The ideas herein are important for young developing cities in Nigeria where urbanization is already ravaging the spaces that are left for development as well as generates ideas for existing megacities like Lagos which ranks in the first 25 largest cities in the world. Urban development has long suffered diminishing effects due to majorly unsustainable initiatives and paucity of innovative solutions in planning and development in Nigeria. Mega cities' ecological footprint as well as their socio-economic and political impact often goes further than comparable medium states. Megacities, which function with the anchor country concept and understood as anchor cities in the context of urbanization, possess huge potential for sustainable regional development, which yet has to be realized and addressed by Nigeria's development initiatives. This paper observes the trends and challenges in modern day Mature and Transitional mega city development, and highlights ideas which Nigerian cities can employ to successfully influence sustainable mega urban development.
\end{abstract}

\section{Keywords}

Urban Development, Megacities, Sustainable Development, Sustainable

Cities, Sustainable Urbanism

\section{Introduction}

Megacities are described as the urban phenomenon of the 21st century. Their exceptional size and density complexities, and their important positions as the 
gateways in the global economy, create huge challenges for sustainable urban development. According to UNDESA, the scale and complexity of global 21st century urbanization are unprecedented as a process in modern human history. A most extensively cited term "urban millennium" brands the future of the planet as a future made up of cities. UNDESA (United Nations Department of Economic and Social Affairs, 2014) recorded the growth of human Urban population growth since 1950 from a meager 746 million to 3.9 billion in 2014 [1]. It also predicted that the human urban population will grow from 2.8 billion in 2000 to 4.9 billion by 2030. By its estimation, more than 900 million of these urban dwellers (nearly one third of the total urban population) who to a very large extent are residing in slums at present, will probably double in number by 2030 often regarded in the popular expression of "a planet of slums" [2]. According to Taylor P., megacities collectively aggregate and amplify all the negative attributes of cities observed within the context of our human settlements [3]. Its growth scale and complexity accrue massively to a degree that makes them ungovernable and vulnerable within environmental, economic, social and political contexts. However, with all the negative impressions, it is often neglected that megacities possess enormous potentials for sustainable solutions with options for positive development, on both regional and international levels.

In Nigeria, Lagos city is referred to as the major mega city. According to the Nigerian National Bureau of Statistics, it is the 8th fastest growing city in Africa. Lagos is recognized globally amongst the 20 largest cities in the world with a population of about 17.5 million people, making it the largest city in Africa with regards to population. Despite the fact that the city currently generates about $25 \%$ of Nigeria's total gross domestic product, coupled with the fact that it accommodates many millionaires, about $66 \%$ of the city's population lives in slums. Lagos city is dubbed the mega city of slums, with millions living in and around its lagoons with no access to roads, efficient transportation, electricity, security, clean water or waste disposal which also impact on the health of occupants. This paper observes these conditions and challenges of mega cities like Lagos, which impact on progressive development owing mostly to unsustainable initiatives and paucity of innovative solutions in planning and development. Through this study, lessons are presented which are basis for solutions to Lagos city and other developing cities in Nigeria.

\section{Research Approach}

The study originated from studies and information generated from the Nigerian National Bureau of Statistics (NBS) on urban development. Information for this study was generated through available Literatures, Reports and Statistics available in the media and Case Studies identified through investigations into current and past trends in mega city surveys. Analysis of the studies and data was presented with the objective of outlining Lessons and Recommendations which will be essential in the discourse on sustainable urban development. Major reports visited include United Nations reports on economic and social affairs (UNDESA), 
FIG Reports, UN-Habitat reports on Informal Settlements, World Urbanization Prospects, Globe Scan reports on mega city challenges and United Nations Millennium Development reports.

\section{Mega Cities and Urbanization Challenges of the 21st Century}

Urbanization and rural to urban migration is a major change that is taking place globally. According to the FIG Report 2010, the expected urban global tipping-point was reached in 2007. This occurred when for the first time in human history over half of the world's population of 3.3 billion people was living in urban areas. It is further estimated that about $60 \%$ of the world's population will be urbanized by the year 2030 [4]. This rush to the cities which is invariably brought about partly by the excessive attraction for opportunities targeted towards wealth generation and economic development is perceived as mainly responsible for the trend and phenomenon of "Mega-cities". Megacities earned its description as urban areas with a population of 10 million people and above. Therefore, it is expected that there will be about 47 megacities by 2020 . UNDESA report already identified that over half of this growth is expected in Asia where the current world's economic geography is shifting. Figure 1 below shows the scale of distribution and growth of megacities in 2015. Lagos Nigeria is ranked as the 11th most populous City from this distribution.

Urbanization is distinctively an irreversible process. The 20th century alone saw the emergence of more megacities with population greater than 10 million. This large population concentration in urban areas is a major historic change. From Figure 1, the number of megacities globally rose from two cities in 1950 to about twenty in 2005. Additionally, seventeen cities out of the twenty megacities globally are located in the developing regions of the world. The major advantages of city life in the past included security, better housing conditions, infrastructure and services. However, all of these have now become major disadvantages of

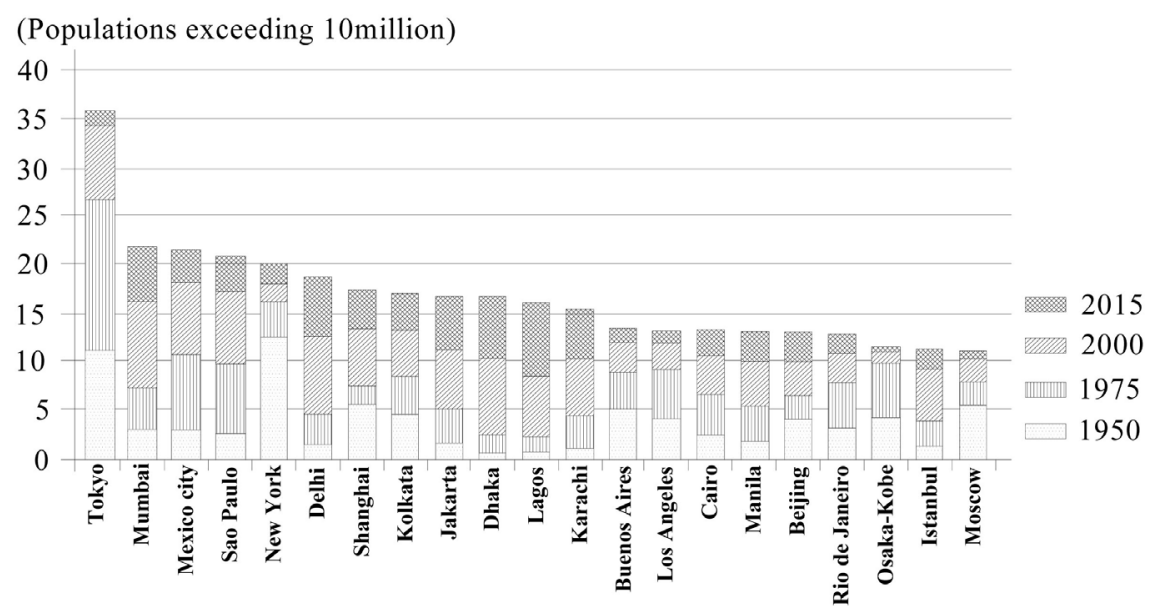

Figure 1. World megacities growth pattern. (Data source: World urbanization prospects: the 2015 revision). 
urban life, with rise in criminality, slums and poorly distributed of services. Coupled with these ills owing to massive displacement of people to megacities are environmental degradation, climate change effects and the shrinkage of areas of land available for agricultural use. It then becomes obvious that sustainable development cannot be achieved without sustainable urbanization.

This study identifies three major trends that evolve during the growth of megacity as it affects the developing countries with interest in the Nigerian urban environment. These trends are outlined as:

1) Infrastructural deficiency: The value of infrastructure and their impact in developing and transitioning economies is a crucial element in urban development. With every bit of expansion of an urban settlement necessitate a relative increase in infrastructure. This subsequently necessitates a need for investment from all sectors of the economy rather than the usual centralized funding of infrastructure as is the case in most developing countries like Nigeria.

2) Transportation congestion: This is identified as one of the major challenges initiated by the growth of megacities. Informal transportation hubs spring out as population expands and tends towards the creation and growth of individual centers or sub-cities. This is a trend that gives rise to many cases of informal cities rampant in emerging economies like Nigeria.

3) Informal settlements: Habitually located in mostly hazardous and high-risk locations, these offshoots of degradation are often the most challenging situations for authorities in developing countries, owing to the difficulties with urban reintegration. The UN report on informal cities (2015), noted that over half of the urban population in Africa (61.7\%) lives in slums [5].

\subsection{Megacity Challenges: An Overview}

According to the United Nations Department of Economic and Social Affairs, at some point in 2018, humanity reached a demographic milestone. Following previous predictions, $55 \%$ of the world population currently lives in cities than the countryside. It is further predicted that $68 \%$ of the world population is projected to live in urban areas by 2050 [6]. Currently, the megacities listed by the UN already have a total population of around 833 million. Though these cities are regarded as the growth engines of their respective national economies, however as these cities and economies grow, so do their challenges. One of the key issues is the burden that growth is placing on urban infrastructures. Unfortunately, the infrastructure in many cities (especially the developing ones) lags behind the population's needs.

In order to uncover and relate the burdens of city growth to the experiences of its inhabitants for the general purpose of deriving significant lessons, this paper would look at available data as well as perspectives from recorded responses from mayors, city administrators and other experts on local infrastructure challenges. The data includes reports from global organizations where public and private sector experts from different disciplines provided insights and the result presents the impacts of population growth in these megacities as major challenge 
for city governments in both emerging and industrialized nations.

One of the reports [7] looks at the challenges facing megacities with regards to city management and critical infrastructure sectors like; Transportation, Electricity, Water and Waste Water, Healthcare, and Safety and Security. The conclusions were based on a survey of stakeholders spread across major 25 megacities across the globe. Furthermore, the survey included general questions on megacity issues which were presented to all the respondents with more detailed sections on specific areas like the five infrastructure sectors mentioned above, as well as city management and finance issues presented to those respondents with the most appropriate knowledge and experience. It measured sample sizes ranging from 124 in transportation and 72 in electricity. To further understand the different challenges facing megacities at different levels of development, this paper analyzes the three city archetypes categorized as:

1) Emerging cities,

2) Transitional cities and

3) Mature cities.

From this review, it was discovered that cities in each of the archetypes listed above (as categorized by the report) share similar characteristics and face similar problems as seen in Table 1 below.

It is the aim of this study also to sheds light on trends and strategies in the five critical areas (mega challenge sectors) of the 25 cities mentioned in the global

Table 1. Mega city categories (Source: Information for this analysis is generated from [7]).

\begin{tabular}{|c|c|c|}
\hline Mega city archetype & Character & Population (size) \\
\hline Emerging Cities & $\begin{array}{l}\text { Characterized by high growth rates driven by } \\
\text { migration and natural growth, much of which } \\
\text { occurs in informal settlements not served by the } \\
\text { installed base of infrastructure and services. } \\
\text { - Social polarity and the gaps in wealth, health, } \\
\text { education, and political power between } \\
\text { groups is generally highest in Emerging cities. }\end{array}$ & $\begin{array}{l}\text { - Annual growth rates are on the order of } \\
\text { between } 3 \% \text { and } 6 \% \text {. A } 3.5 \% \text { growth rate } \\
\text { implies a doubling of population in } 20 \text { years. } \\
\text { - This includes countries with urban populations } \\
\text { of less than } 50 \% \text {. Populations tend to be } \\
\text { younger and more male, with a high } \\
\text { proportion of poorly educated rural migrants. }\end{array}$ \\
\hline Transitional Cities & $\begin{array}{l}\text { - Often developed mechanisms to more effectively } \\
\text { manage dynamic growth, and may be seeing } \\
\text { a slowing of annual growth rates. } \\
\text { Transitional cities have similar infrastructure } \\
\text { challenges as compared with Emerging cities but are } \\
\text { better able to respond financially and organizationally. } \\
\text { - Increasing affluence in these cities places additional } \\
\text { new demands on infrastructure as growth in } \\
\text { demand for transportation, water, energy, and } \\
\text { services often greatly outpaces population growth. }\end{array}$ & $\begin{array}{l}\text { - Continued population growth stems largely from } \\
\text { migration, with lower natural population increases } \\
\text { - Several of these cities are seeing the first signs } \\
\text { of an ageing population. } \\
\text { - Growth rates are typically of the order of } 2 \%-3 \% \\
\text { per annum and Transitional cities are often in } \\
\text { countries that are more than } 50 \% \text { urbanized. }\end{array}$ \\
\hline Mature Cities & $\begin{array}{l}\text { - Have built out their basic infrastructure to } \\
\text { serve their populations one or two generations ago. } \\
\text { With high-quality infrastructure in place the challenge } \\
\text { has shifted to coping with the need for renewal of } \\
\text { ageing systems or to dealing with obsolescence } \\
\text { where the installed infrastructure no longer } \\
\text { meets regulatory requirements. }\end{array}$ & $\begin{array}{l}\text { Mature megacities have much slower growth rates } \\
\text { than both Emerging and Transitional megacities, } \\
\text { at around } 1 \% \text { on average. } \\
\text { In some of these cities, the population has } \\
\text { stagnated or is shrinking. Mature megacities } \\
\text { also have older population profiles. } \\
\text { - They exist in countries that are typically } \\
\text { around } 75 \% \text { urban. }\end{array}$ \\
\hline
\end{tabular}


research project. All cities need high-quality infrastructure to facilitate the movement of people and goods, and the delivery of basic services to their populations. But the challenge of delivering these infrastructures and services in today's megacity regions is immense. This is true for Mature cities where, for example, roads, rail networks, sewers and hospitals were often built decades or even centuries ago and in some cases are now becoming increasingly unfit for its purpose. It is also true of the Transitional cities, which are struggling to cope with demographic changes, and Emerging cities where even basic services are badly lacking, particularly in the rapidly expanding informal settlements. Moreover, in all three city archetypes there are complex issues to be resolved over the funding, management, maintenance and efficient running of services, as well as the need to find infrastructure solutions that are environmentally sustainable.

This study of identified that certain infrastructural sectors are mostly affected by inadvertent growth of cities. These key infrastructural sectors are as follows:

\subsubsection{Transportation}

Transport and growth of urban areas are strongly related. It is common knowledge that population growth is resultant to increase in urban trips and the consequent travel demand in cities. According to report in [8], the average US household budgets around $18 \%$ of its income for road transportation only, while the government on the other hand, spends close to 200 billion dollars annually on same. Also for over 20 years, increase in employment rate to the tune of $1.5 \%$ resulted in $10 \%$ increase in capital stock on interstate highways. The total value of capital stock on US road transportation expenditure hits above 5 trillion dollars [9], this demonstrates the magnitude of economic value on transportation as impacted by population growth. The review in [7], marks transportation as the single biggest infrastructure challenge faced by cities. That rating is particularly high with $45 \%$ for mature cities and $43 \%$ for Transitional cities. Take Europe for example, car ownership in the EU rose to about 10 times more quickly than the population growth over the past 10 years. However, in Emerging cities, the emphasis on transport from the responders is less pronounced, with about $17 \%$ which is still above that of the other infrastructural sectors such as water (8\%) and electricity (5\%). With regards to investment, Transportation is also the priority for spending, in the survey, about $86 \%$ of stakeholders cited it as a vital area for investment. Stakeholders in the survey are highly aware of the importance of transportation networks in driving the economy with about $27 \%$ mentioning transportation as the number one area of a city's infrastructure that is most critical to investment attraction, way ahead of the second most cited concern which is Safety and security with $9 \%$. Major causes of megacity transportation challenges are reported in Figure 2.

\subsubsection{Electricity}

Energy and access to electricity are considered as the strings that weaves together economic growth and human development. The growth of cities and economies 


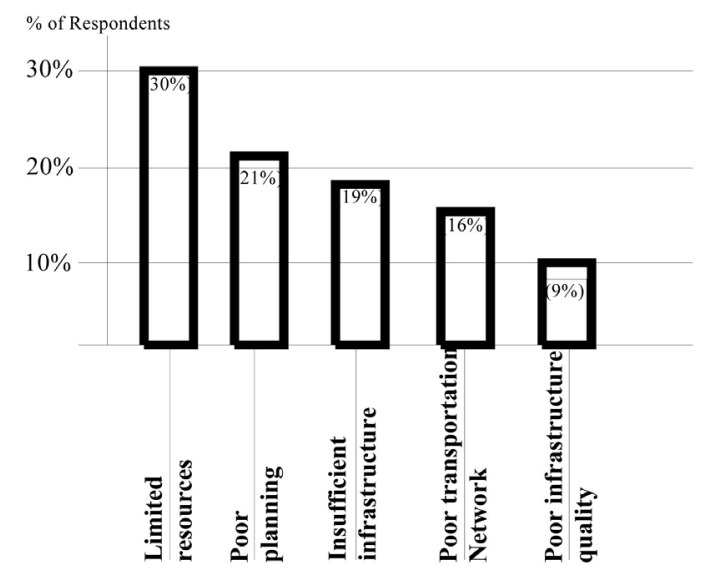

Figure 2. Main cause of megacity transportation problems in the survey (Source: Information for this analysis is generated from GlobeScan and MRC McLean Hazel (2004) $[7])$.

is strongly dependent on the electricity infrastructure they are able to muster. Through the adoption in 2015 by 193 countries on accessibility to affordable, reliable, sustainable and modern energy for all by the year 2030, this marked a new level of political recognition as part of the new United Nations Sustainable Development Goals [10]. The International Energy Agency in its 2017 report, predicts the exponentiation of electricity demand by 2030 worldwide. Most of this increase is expected to occur in the rapidly growing economies of India and China. While countries like china reached full electrification in 2015, electrification efforts in sub-Saharan Africa on the other hand, outpaced population growth for the first time in 2014, leading to a decrease in the number of people without access to electricity in the region. Despite these efforts, Africa is currently just at $43 \%$. According to the International Energy Agency report, United Nations Sustainable Development Goals (SDGs) recognizes the integrated nature of development and electricity infrastructure. The lack of access to modern energy can make it difficult or impossible for countries to meet the numerous challenges it faces. Such challenges are poverty (SDG 1), air pollution, low life expectancy levels and the lack of access to essential healthcare services (SDG 3), quality education (SDG 4), mitigation of climate change (SDG 11), food production and security (SDG 2), employment and economic growth (SDG 8), sustainable industrialization (SDG 9), and gender inequality (SDG 5).

The review in [7] identified that only $2 \%$ of respondents in the survey believe electricity supply is their most serious infrastructure challenge. However, the value of investment in this area ranks below other fields as transportation, water, education, public housing and security. As the case was, only Emerging cities see the issue of electricity as much more important. Electricity stakeholders in Transitional and Mature cities see old or obsolete infrastructure as their main problem. This is followed by efficiency, and lack of capacity. Some of the challenges weak infrastructure can pose on the power system can be observed in the case of richer cities like New York. Here, the law requires that $80 \%$ of power must be 
generated in the city because transmission lines expected to bring electricity from outside simply cannot cope with the higher load. On the other hand, in Emerging cities, the lack of sufficient generating capacity is by far the most challenging concern. While Emerging city stakeholders points to late maintenance services and lack of planning as the major factor in their challenges, those in Transitional cities blame lack of investment. According to the survey, Lagos (Nigeria) is regarded as an excellent example of how all these problems work together. Due to little investment since 1990, the 6000 MW maximum generation capacity cannot meet the $8500 \mathrm{MW}$ that the city requires on average before even considering repressed demand of $5000 \mathrm{MW}$. Worse still, poor maintenance means that the actual output averages about $3000 \mathrm{MW}$. This entirely means that $45 \%$ of power is lost in the poorly maintained and frequently vandalized transmission system in the case of Lagos (Nigeria) (Figure 3).

\subsubsection{Water and Waste Water}

The United Nations Committee on Economic, Social and Cultural Rights declares that the human rights to water entitles everyone to sufficient, safe, acceptable, physically accessible and affordable water for personal and domestic uses [11]. These attributes not only represent the core foundations for water security, they also represent the fundamental benchmarks for the most widely violated human right across a large section of humanity. As stated in the Articles 11 and 12 of the Rights to Water Covenant, over 1 billion persons worldwide lack access to a basic water supply, while several billions do not have access to adequate sanitation, which is identified as the primary cause of water contamination and diseases that are linked to water. It further stated that the continuing contamination, depletion and unequal distribution of water are exacerbating existing poverty globally. Hence tasking individual States to adopt effective measures towards realize, without discrimination, the right to water, as set out in this general comment. For these 1.1 billion people mentioned in the article, the benefits of sufficient, safe, acceptable, accessible and affordable water is a hope for the future and not a reality for the present of humankind.

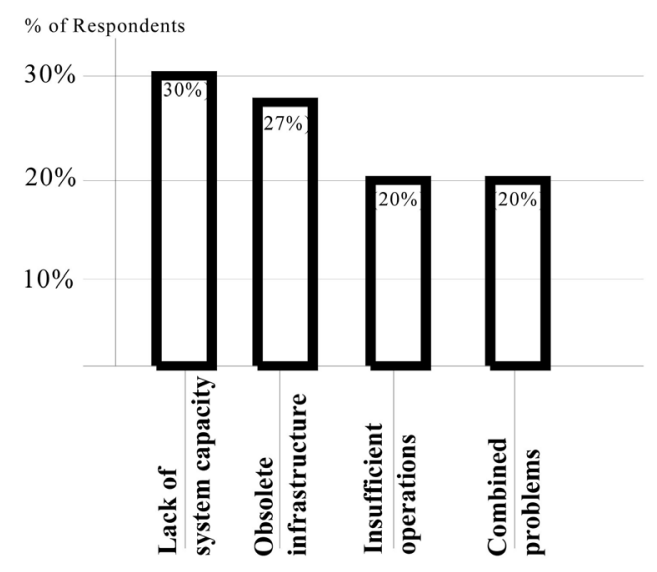

Figure 3. Main cause of megacity electricity problems in the survey (Source: Information for this analysis is generated from GlobeScan and MRC McLean Hazel [7]). 
In mostly the transitional and especially emerging cities, the UNDP estimated that over 2.6 billion people, roughly $40 \%$ of the world's population, had no access to improved sanitation. For example, data for Jakarta and Nairobi both indicate $90 \%$ coverage for clean water and sanitation, however, this data leaves out huge areas of slum dwellers. In the case of Jakarta, some 7.6 million people live without such facilities [12].

The Globe Scan survey data demonstrated in Figure 4, reflects the different experience of respondents across the archetype cities. Respondents' reply to the most serious infrastructure challenges facing their cities saw water related issues split into two separate categories of water supply and wastewater management. The combination of these constitutes the third most frequently cited issue at $8 \%$. This figure nevertheless puts it far behind transport as a perceived challenge at $35 \%$. In the case of emerging cities for instance, water issues come second with $13 \%$, in mature cities nonetheless, they appear as low as $3 \%$. Equally, the overall water pollution and water quality is listed as the fourth largest environmental challenge with 13\%, but comes second in Transitional cities where it reported $22 \%$.

\subsubsection{Healthcare}

Developing countries account for about $84 \%$ of global population, with $90 \%$ of the world's disease load and just $20 \%$ of global GDP. While Developing countries account for only $12 \%$ of global health spending, the poorest countries records $56 \%$ of the global disease load with only $2 \%$ of spending [13]. While the developing countries are struggling under a large burden of communicable disease and confronting rise in other non-communicable diseases (a vicious trend), the availability of resources to meet these numerous health needs is limited. These low income countries are dependent on the international community for levels of donor assistance in the health sector in order to ensure that adequate resources are available for increased spending in essential health services objectified in the Millennium Development Goals. On the other hand, middle income

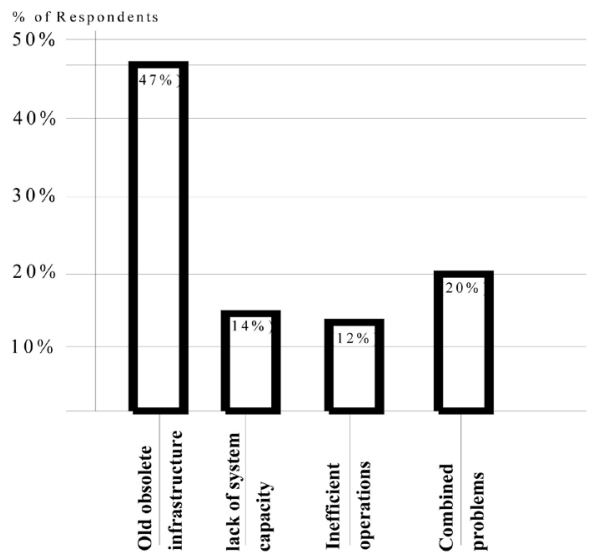

Figure 4. Main cause of megacity water supply and wastewater management problems (Source: Information for this analysis is generated from GlobeScan and MRC McLean Hazel (2004) [7]). 
countries mostly with growing working age populations, face the challenge of providing adequate employment to balance its challenges, although the increased life expectancy heightens demand on the other end of the age range. Conversely, developed countries will always be faced with growing proportions of the elderly and its rapidly rising health expenditures. This challenge is compounded by the concerns on how the declining working age population will support the health and social services demanded by the increase in numbers of their elderly, coupled with the growing reliance and liabilities of publicly financed health and pension systems.

With this collective analysis, it is obvious that the Healthcare challenges in megacities reflect their broader national environments. The situation perceived in emerging cities like Lagos in Nigeria, reveals severe unavailability of basic infrastructures. In the case of Lagos, its health system cannot even provide basic needs in the face of serious cases like AIDS, tuberculosis, and malaria. Transitional cities on the other hand, are doing better as this city archetype faces medical problems associated with more development-oriented cultures like the effects of pollution arising from industrialization, as is the case in Shanghai. In the same view, mature cities such as New York, with its high concentrations of hospitals, are troubled by healthcare inflation and diseases such as obesity, diabetes and cardiovascular problems often classified as the disease of affluence. Despite the scale of these challenges, healthcare is observed as lesser of a priority for respondents in the overall survey in [7]. In the list of social challenges, it measured very low, as it was mentioned by only $4 \%$ of the respondents while infrastructure challenges were mentioned by only $1 \%$. The biggest challenges facing healthcare systems in cities as seen in Figure 5, was mentioned in the survey as lack of capacity, followed closely by inefficient operations which was mostly marked among stakeholders from Emerging cities.

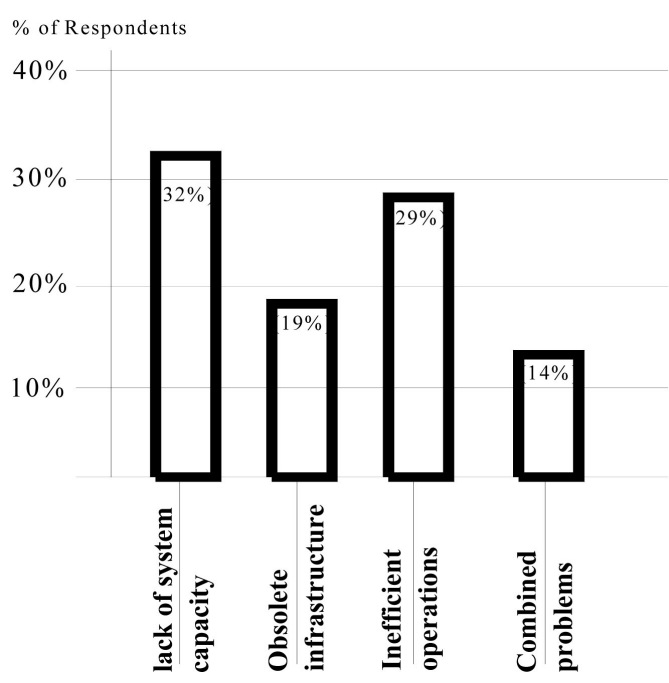

Figure 5. Main cause of megacity healthcare sector problems in the survey (Source: Information for this analysis is generated from GlobeScan and MRC McLean Hazel (2004) [7]). 


\subsubsection{Safety \& Security}

Mega cities characterized by high-density populations are often more prone to varieties of security threats and disasters than smaller cities. Though the efficient integration of resources and provision of social services may improve the quality of life in these large cities, the very lushness of its resources in itself is a source of vulnerability to a broad range of kinds of disasters. More so, the services provided by critical infrastructure in mega cities make it possible for the millions of its inhabitants to live close together, to the extent these cities can protect, control, and manage its energy needs, water, communications, medical, transportation as well as emergency services. These services referred to as critical infrastructure in the structure of cities are both vulnerable and interdependent. Consequently, the range of natural disaster impacts that knocks one of these infrastructures like electric power, rail lines, telecommunications, major gas and water conduits, is basically comparable to a terrorist attack on these infrastructures [14]. To this end, the benefits of megacities lie strongly on the ability to provide safety and security to their inhabitants, as well as economic opportunity and social services.

In the study in [7], organized crime is recognized as the biggest security challenge for megacities. Its impact is demonstrated through the stakeholder's survey, behind those who mentioned terrorism as the second most prominent issue. The survey population however ranked public safety and security as the second most important infrastructure area in determining urban competitiveness with 9\% mention by the respondents. On the other hand, crime and corruption comes in tenth. This study was able to deduce from the survey answered by security stakeholders that organized crime is their biggest challenge as mentioned by $36 \%$ of respondents(see Figure 6), with higher numbers in the Emerging and Transitional cities.

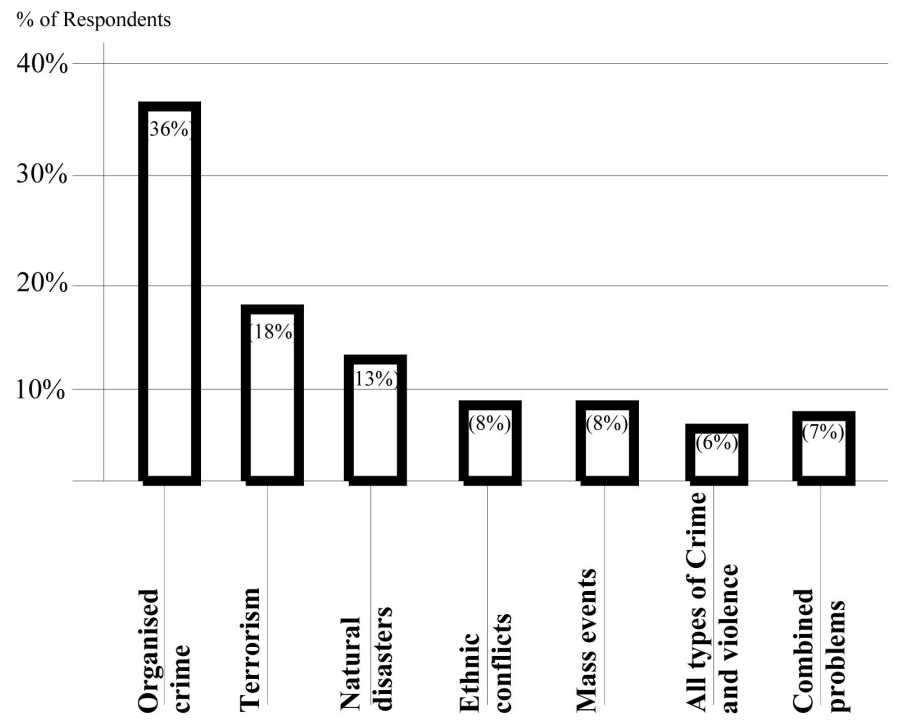

Figure 6. Main safety and security problems in the survey (Source: Information for this analysis is generated from GlobeScan and MRC McLean Hazel [7]). 
The other pressing concern is safety relative to potential natural disasters. About 13\% of respondents named natural disasters as their city's leading security challenge. Conversely, mature city respondents rank it as high as other challenges, while emerging city respondents did not mention it. This does not mean that the emerging cities are not exempt from potential disasters. For example, Lagos will lose significant territory if global warming raises sea levels [15] yet it appears to be the least of the city's worries. Moreover, with a barely functioning security apparatus, Lagos cannot even properly address current annual floods.

The study of the Infrastructural challenges by different megacity archetypes can be summarized as follows:

1) Transportation ranks highest in all the categories of archetypes as the biggest infrastructural challenge. This puts transportation as the most vital area for investment and spending in megacities.

2) Secondly follows Safety and Security. Owing to the challenges of natural disasters, crime and terrorism, all megacity archetypes see the challenges of safety and security of occupants as the second most demanding aspect of urban development.

3) Thirdly is Water and waste water management. Transitional and Emerging megacity archetypes deal with either the problems of sufficient, safe or accessibility of affordable water supply more than the already advanced Mature megacities.

4) In the fourth place of the biggest challenges of megacity infrastructure is Electricity. The challenges of electricity provision are mostly rampant in the Emerging megacity category. The Mature and Transitional cities have advanced in terms of Electricity generation and its infrastructural development.

5) Finally, the least notable challenge is Healthcare. Although only the emerging city category still battles with basic healthcare provision, it is yet seen as the least (with regards to) social challenges in these five urban infrastructural problems met by megacities.

\subsection{Megacity Challenges and Challenges to Metropolitan Governance}

Management absolutely affects how well modern civilization functions. City governance has become increasingly complex as cities evolve into separate agglomerations with multiple administrative councils and jurisdictions. Historically, administrative boundaries may have been fixed at periods when most cities were physically and administratively smaller than they are today. However, with decades of migration and the physical expansion of their boundaries, metropolitan administration becomes more complex [16]. With growing urban policy reforms on Metropolitan governance, the challenges of city governance can be highlighted as:

1) Defining Jurisdiction of municipalities,

2) Funding

3) Public Participation and 
4) Interjections from other levels of government.

Owing to the challenges of infrastructural overburden on Megacities, they are often overwhelmed with the problems of funding more than other challenges in its administrative governance approaches. This often calls for the need for innovative funding strategies to discharge much-needed investment to address the infrastructure challenges discussed in 2.1 above. Although these situations are widely acknowledged, there is still considerable debate about how to address these challenges. Individual City government must develop and adopt unique finance structures to meet the unique circumstances and needs of each city according to its development strategy.

In a 2007-2008 research study on problems facing city administrators, data were obtained from seven cities (Hong Kong, Tokyo, Seoul, Istanbul, London, New York and Lagos) either by their direct response to the questionnaire (Q) or by personal visits $(\mathrm{V})$ and interviews by the authors and contributors [4]. Table 2 shows the information derived from that stage of research. Also discovered is the factor of informal settlements in most megacities, mainly in countries where development controls, housing policies and tenure systems are immature and land administration capacity is low. Some of the experience with planning and

Table 2. Key problems facing megacity administrations (Source: The information for this analysis is generated from International Federation of Surveyors (FIG) Report 2010).

\begin{tabular}{|c|c|c|c|c|c|c|c|}
\hline Problem & $\begin{array}{l}\text { Hong } \\
\text { Kong } \\
(Q)\end{array}$ & $\begin{array}{l}\text { Tokyo } \\
(\mathrm{Q})\end{array}$ & $\begin{array}{l}\text { Seoul } \\
(\mathrm{Q})\end{array}$ & $\begin{array}{l}\text { Istanbul } \\
(\mathrm{Q})\end{array}$ & $\begin{array}{l}\text { London } \\
\text { (Q) }\end{array}$ & $\begin{array}{l}\text { New } \\
\text { York } \\
(Q)\end{array}$ & $\begin{array}{c}\text { Lagos } \\
(\mathrm{Q})\end{array}$ \\
\hline $\begin{array}{l}\text { Informal settlements } \\
\text { (land tenure, development } \\
\text { approvals, building control) }\end{array}$ & $\mathrm{N}$ & $\mathrm{Y}$ & $\mathrm{N}$ & $\mathrm{Y}$ & $\mathrm{N}$ & $\mathrm{N}$ & Y/High \\
\hline $\begin{array}{l}\text { Traffic management } \\
\text { and control }\end{array}$ & Y/Medium & $\mathrm{Y}$ & $\mathrm{Y}$ & $\mathrm{Y}$ & $\mathrm{Y}$ & $\mathrm{Y}$ & Y/High \\
\hline $\begin{array}{c}\text { Natural hazards } \\
\text { (floods, earthquakes, fires) }\end{array}$ & $\mathrm{N}$ & Y & $\mathrm{Y}$ & $\mathrm{Y}$ & $\mathrm{Y}$ & $\mathrm{Y}$ & Y/High \\
\hline $\begin{array}{l}\text { Unclear responsibilities } \\
\text { and mandates (within or } \\
\text { between administrators) }\end{array}$ & $\mathrm{N}$ & $\mathrm{N}$ & $\mathrm{N}$ & $\mathrm{N}$ & $\mathrm{N}$ & $\mathrm{N}$ & Y/High \\
\hline Uncoordinated planning & $\mathrm{N}$ & $\mathrm{N}$ & - & $\mathrm{N}$ & $\mathrm{N}$ & $\mathrm{N}$ & Y/High \\
\hline $\begin{array}{l}\text { Water management issues } \\
\text { (both fresh water supply } \\
\text { and waste water disposal) }\end{array}$ & Y/Medium & $\mathrm{Y}$ & $\mathrm{N}$ & $\mathrm{Y}$ & $\mathrm{N}$ & $\mathrm{N}$ & Y/High \\
\hline $\begin{array}{c}\text { Provision of } \\
\text { continuous electricity }\end{array}$ & $\mathrm{N}$ & Y & $\mathrm{N}$ & $\mathrm{N}$ & $\mathrm{N}$ & $\mathrm{N}$ & Y/High \\
\hline $\begin{array}{l}\text { Visual pollution } \\
\text { and refuse disposal }\end{array}$ & Y/Medium & $\mathrm{Y}$ & $\mathrm{N}$ & $\mathrm{N}$ & $\mathrm{N}$ & $\mathrm{Y}$ & Y/High \\
\hline $\begin{array}{l}\text { Air and water } \\
\text { pollution control }\end{array}$ & Y/Medium & $\mathrm{Y}$ & $\mathrm{Y}$ & $\mathrm{N}$ & $\mathrm{Y}$ & $\mathrm{Y}$ & Y/High \\
\hline Population growth & - & $\mathrm{Y}$ & - & $\mathrm{Y}$ & $\mathrm{Y}$ & Y/Low & $\mathrm{Y}$ \\
\hline
\end{tabular}


development laws, regulations, procedures and systems used in most of the better functioning Mature and Transitional cities may be useful to others in terms of governance. From the study of the research on city administration in the FIG report, it appears that unclear responsibilities and mandates often observed within or between levels of administrations were not issues for concerns, however issues of overlapping responsibilities amongst internal and external agencies is identified as primary challenge, leading to operational dysfunction resulting in situations like numerous agencies holding non-accessible spatial data. It is thus clear that solutions to problems facing megacities require combined response from many internal units in combination with regional and national agencies in areas such as planning, infrastructure, development and land use controls, transportation, environmental management and water management. As often the case, mandates may be clear in administration levels, but rationalization of functions and more effective levels of cooperation lack. Through all observation, it seems that in many megacities, the city administrations do not have responsibility for most matters covering the full area of the cities. FIG Report [4], reported that several cities claimed that their administrations did not have control over development, but rather it was the responsibility of subsidiary local government units. Cases are available where other levels of government had land use and development control responsibilities. In this case, even if city planning services is centrally coordinated, often city administrations have little control over the implementation on land use and building controls sections of these plans.

\section{Further Lessons on Sustainable Solutions to Megacity Problems}

This paper narrates some of the measures and solutions implemented in some megacities as ideas which can be adopted in the case of emerging cities 'development initiatives.

The lessons which can be drawn from Asia are believed to be most applicable in the case of Nigerian urban development, owing to the speedy development trends experienced in many Asian cities. Some of these ideas include:

\subsection{Structural Adjustment in Urban Development}

In Asian megacities (which are mostly classified under Transitional city category), it is quite evident that the growth of the urbanization is very dependent on radical spatial, social and political structural changes and these are associated with the economic rise of the whole region since the mid-1980's. These changes are connected with:

1) Accelerating migration processes

2) Growing proportions of secondary and tertiary activity as well as extensive development of transport and communications infrastructure connected with growing global interdependence, improvements in health care and education, 
expanding economic middle classes, socio-economic disparities as well as growing poverty and crime rates.

3) Excessive spatial expansion, as carry-along initiative in connection with the emergence of informal settlements and slums,

4) Loss of governability and control, leading to more unregulated processes which take place informally or illegally.

\subsection{Urbanization Boost}

By the year 2025, it is expected that China will have the class of eight mega cities which will include Beijing, Shanghai, Chengdu, Chongqing, Guangzhou, Shenzhen, Tianjin and Wuhan all of which will have a population of more than 10 million each, according to international management consultants [17]. This explosion expected in China, will be part of a massive urbanization trend that will see up to 325 million more humans living in cities in less than a generation. Managing the likes of such an explosion then becomes the future challenges for a development hungry China. According to $\mathrm{Wu}$ Changhua, the Greater China director (former) of The Climate Group, an international environmental lobby organization, said it was possible to deliver energy and essential services more efficiently to concentrated urban areas. She feels that Urbanization can be regarded as one of the solutions to energy and climate change issues and through it, cities can achieve a much more efficient use of energy. In her view, planners in China have the opportunity to fashion new cities that will be effectively carbon neutral, making use of state-of-the-art technology as the speed of China's development will still make it hard for urban planners to contain the environ mental risks, but still enjoys the opportunities of a developing environment (unlike the US whose cities have already gone beyond the mark of development). Also according to McKinsey [17], by 2030, 120 million people will live in China's megacities. This demonstrates an increase from 34 million in 2007 when only Beijing and Shanghai were classified in the megacity category. Cities like Chongqing for instance, which could be set to be China's first 30 million population city, has been growing at six times the rates it took a city like Chicago to develop in its 50 years before 1900. Chongqing has grown from a collection of towns and villages to become one of the world's greatest new conurbations and megacity giant.

\subsection{Car-Free Sustainable City Initiative}

Study in [18] predicts that China will overtake the United States as the world's largest economy by 2050. It also predicted the emergence of megacities which will create huge challenges demanding the evolution of novel solutions to these new challenges posed by this rate of development. With this situation in china, it is evident that cities cannot be built around cars, because expectant car ownership levels in China when grown up to its western counterparts will result in complete stagnation of its cities. 


\subsection{Cluster Cities to Megacity Transition}

In another related perspective, Ma Xiaohe the vice-president (2016) of the Academy of Macroeconomic Research at the National Development and Reform Commission of China in Beijing envisages megacities emerging with small and medium sized cities in small clusters. With this development, the larger cities (megacities) can then share resources with the small and medium sized cities creating logistical benefits and a big labor pool which will result in reducing overall costs in the management of these large cities.

In the light of these ideas, many cities in China are already developing innovative solutions to most of its megacity challenges. For instance, through a technical cooperation with the METRASYS project aimed at developing and implementing a sustainable mobility strategy for mega cities, some of China's traffic and transportation based challenges are getting innovative attention with such ideas as:

- Intelligent Transportation Systems (ITS) projects

- Express lines, inner city and regional express railways as well as high-speed railways

- And the encouragement of more zero carbon initiated traffic systems.

\section{Promoting Innovative Solutions for Nigerian Cities in Planning and Development Following Pending MDG Calls for a Re-Thinking of City Development}

Through the analysis of the reports mentioned above, much deficiency can be observed in the case of the Nigerian megacity scenario. With a city like Lagos classified under the Emerging city category, majority of its city development problems could easily be attributed to the unsustainable initiatives and paucity of innovative solutions in planning and development (even to the degree of governance). An overview of a ten-class problem list generated for Lagos city and with a view on the level of deficiencies observed in the governance sector was developed and compared with the six parameters analyzed in this paper. Table 3 shows the degree of performance in comparing the six exclusive parameters analyzed in 2.1 .

However, to successfully meet up with the challenges of today's megacity challenges, it is important for the Nigeria-city policy makers and development agencies alike, to decide on the general direction which to turn to and at the same time stay flexible and open for changes. Description in [19], emphasizes the role of openness towards influences from the outside, cultural plurality, freedom and opportunities for participation, as sources of creativity and innovation that will spur positive development. It is noteworthy that a global level city performs better than a local city for a given quality of governance, but still a city can be well-performing whether local or global driven, by its good governance alone. The basic factor for success may lie therefore, in the abilities of the municipality in governance or management of their cities [20]. As a consequence, 
Table 3. Degree of deficiency in the Lagos megacity scenario.

\begin{tabular}{cc}
\hline Problem & Degree of deficiency \\
\hline Informal settlements & High \\
Traffic management and control & High \\
Natural hazards (floods, earthquakes, fires) & High \\
Population growth & High \\
Uncoordinated planning & High \\
Water management issues & High \\
Provision of continuous electricity & High \\
Visual pollution and refuse disposal & High \\
Air and water pollution control & High \\
Governance and administration & High \\
\hline
\end{tabular}

furthering effective metropolitan management must be the key feature for sustainable megacity development. Obviously, a well-functioning infrastructure which can be taken as an indicator for the quality of governance is an essential prerequisite to participate in globalization and sustainable economic development. Dialogue in [3] described infrastructure and governance as two sided; the "hard" and "soft". It classified the soft infrastructure as qualitative tools such as steering skills, flexibility and openness. On the other hand, one vita land most effective tool for the improvement of governance quality is capacity building. This is evident in the grave deficits often found regarding qualified and efficient administrative staff, including decision makers, and connectivity to other stakeholders outside administrations. In other words, there is a need to improve "soft" infrastructure in the case of Nigerian-cities in the dream of evolving into a sustainable megacity of the future. The strategies which can be adopted or developed are innumerable and each city has to find the most suitable ones for its local scenarios. However, the ingredients are remarkably common. The practice of providing knowledge about practices that may have worked elsewhere, sharing experiences, advancing local capacities and offering decision support systems are functions that are relevant in the achievement of these goals which unequivocally focuses on the Millennium Development Goals (MDGs). It is thus essential for local Nigeria researchers and practitioners to work towards providing such knowledge and support structures.

For the Nigerian-city researchers, the challenge on achieving sustainability in its local urbanization trends may still enjoy the evolution stage (as emerging cities/economy status) of its mega and smaller cities to produce a more sustainable environment for living. With its emerging economic potential, and huge population advantage coupled with diversity of its demographics, Nigerian cities are fertile grounds for experimentation and exploits of new ideas. However, the need and quest for development must be met with cautious steps. The process of 
global learning is how innovations once identified may be meaningfully transferred to others with enabling conditions necessary to maximizing the chances of effective replication. The enabling conditions for successful transfer should thus include factors like:

1) Prudence in management and financing innovative ideas,

2) Involving indigenous organizations,

3) Developing possible peer support through meetings of innovators within and among cities,

4) The process of changing the incentive systems in government towards rewarding innovation through recognition, support and publicity,

5) Engaging and empowering product champions to advocate for the needed change,

6) Consistently providing an accessible knowledge base to draw upon,

7) Applying the principles of cautious monitoring, evaluation and reporting systems during development processes.

\section{Conclusions and Recommendations}

This paper identified the megacities archetypes associates with urban development as Mature, Transitional and Emerging categories. It further identified the major challenges faced by each category and collective categories with regards to infrastructural development. Whereas transportation is identified as the biggest challenge and major investment sector, safety and security, water and waste management, electricity and health follow respectively in ranking of difficulty. It also presented the experiences and challenges of metropolitan governance as well as lessons learnt from ideas utilized in Asian Transitional megacities adoptable in the case of Nigerian urban development. With the review of experiences of different categories of megacity inhabitants as it regards population growth and development, mega cities can be described as eager to prioritize economic competitiveness and employment, while sacrificing the environment for growth. On the other hand, improvement of governance will always be vital towards creating better cities, hence broad holistic solutions are vital for improvement of services, however the challenges of managing demands.

Extensive literature exists on the government efforts for better city-environment initiatives in Nigeria. A clearer example is the case of Lagos city where development initiatives are drawn almost annually but this is devoid of implementation. In urban planning terms, the highest development dynamics of any city take place in the inner city and urban fringe areas. Urban fringe areas of fast growing agglomerations are considered to be among the hotspots of urban transformation as they are areas that are still not fully urbanized but will be so in the foreseeable future. This paper recognizes the advantage of the youthfulness of Nigerian cities, acknowledges that the development trajectories of future urban areas depend on decisions made at a very early stage by different actors and stakeholders and presents the experiences of megacities and challenges faced by other 
more evolved countries as footstool for its sustainable urbanization. It is evident that processes leading to land use change can become irreversible and can lead to unsustainable development, hence political decision making processes in the Nigerian scenario thus require substantial attention at an early stage.

Finally, for an emerging economy like Nigeria and its cities to attain the heights of the MDGs expectations which require particularly mega-urban areas to be responsible as engines and trendsetters for the development of other areas, Vertical and horizontal integration and cooperation should be adopted as prerequisites for effective development. Through development cooperation and lessons learnt, experience-based ways for reaching compromises and means of solution can be exploited, especially in the face of the growing number of actors involved in making the urban system work. Such initiatives as the Cluster-cities to megacity, Anchor-city concepts or Multi-center megacity initiatives are ideas that support these systems of development. In this case, emerging cities can take a cue from Mega-urban regions, especially in China's Pearl River delta and the US central east coast that grew through the creation of clusters of cities or system of cities. If these concepts and systems worked in other regions, then why not the evolution of Nigerian-megacities through the traditional form of center and suburbs will form multi-centered megacity dimensions. These systems of urban areas which can easily evolve from the modern Nigerian-city scenario, if developed will exhibit both a strong internal and international spatial-economic relationship.

\section{Conflicts of Interest}

The author declares no conflicts of interest regarding the publication of this paper.

\section{References}

[1] United Nations Department of Economic and Social Affairs (UNDESA) Population Division (2005) World Urbanization Prospects: The 2014 Revision. 2014 WUP Highlights. https://esa.un.org/unpd/wup/publications/files/wup2014-highlights.pdf

[2] Davis, M. (2006) Planet of Slums. Verso, London.

[3] Taylor, P. (2006) The Role of Megacities in Development-Opportunities and Risks. International Dialogue. Governing Emerging Megacities-Challenges and Perspectives. InWEnt, Berlin.

[4] International Federation of Surveyors (FIG) Report (2010) Rapid Urbanization and Mega Cities: The Need for Spatial Information Management. Research Study by FIG Commission 3. International Federation of Surveyors (FIG), Copenhagen.

[5] UN-Habitat (2015) Habitat III Issue Papers; 22-Informal Settlements. New York.

[6] World Urbanization Prospects: The 2018 Revision. 2018 WUP Highlights. https://population.un.org/wup/Publications/Files/WUP2018-KeyFacts.pdf

[7] GlobeScan and MRC McLean Hazel (2004) Megacity Challenges-A Stakeholder Perspective. A Research Project Conducted by GlobeScan and MRC McLean Hazel Sponsored by Siemens. Siemens AG, Munich.

[8] Duranton, G. and Turner, M.A. (2012) Urban Growth and Transportation. Review 
of Economic Studies, 1, 1e36.

[9] United States Bureau of Transportation Statistics (2010) Transportation Statistics Annual Report 2010. US Government Printing Office, Washington DC.

[10] International Energy Agency (2017) Energy Access Outlook 2017; World Energy Outlook Special Report. https://www.iea.org/weo2018

[11] United Nations Economic and Social Council (2003) Committee on Economic, Social and Cultural Rights; Report on the Twenty-Ninth Session, E/C.12/2002/11. New York and Geneva.

[12] Watkins, K. (2006) Beyond Scarcity: Power, Poverty and the Global Water Crisis. UNDP Human Development Report 2006. Palgrave Macmillan, New York.

[13] Mathers, D., Ezzati, M., Jamison, D.T. and Murray, C.J.L. (2006) Global Burden of Disease and Risk Factors. World Bank, Washington DC, Oxford University Press, New York.

[14] Branscomb, L.M. (2006) Countering Urban Terrorism in Russia and the United States: Proceedings of a Workshop 2006. National Research Council. The National Academies Press, Washington DC. https://doi.org/10.17226/11698

[15] Spurgeon, J., Wasilewski, C., Ikpi, A. and Foster, S. (2009) Impact of Climate Change on Nigeria's Economy, Final Report. DFID (Department for International Development), ERM, Oxford.

https://www.scribd.com/document/47086875/27-Impact-of-Climate-Change-on-Ni gerias-Economy

[16] Secretariat General, Democratic Governance Directorate Council of Europe (2017) Overview of Metropolitan Governance; Paper for the Parliamentary Committee on State Building, Regional Policy and Local Self-Government, Ukraine. Strasbourg, CELGR/LEX (2017) 1.

http://www.slg-coe.org.ua/wp-content/uploads/2017/04/CoE-Overview-of-metropo litan-governance-CELGRLEX-201711.pdf

[17] McKinsey and Company (2009) Preparing for China's Urban Billion. McKinsey Global Institute, Shanghai.

[18] Jacques, M. (2009) When China Rules the World: The End of the Western World and the Birth of a New Global Order. Penguin Press, London.

[19] Hall, P. (1998) Cities in Civilization. Culture, Innovation and Urban Order. Weidenfeld \& Nicolson, London.

[20] Leautier, F. (2006) Megacities in a Globalizing World. International Dialogue. Governing Emerging Megacities-Challenges and Perspectives. InWEnt, Berlin. 